\title{
INFLUÊNCIA DO SOMBREAMENTO SOBRE OS TEORES DE CARBOIDRATOS E FENÓIS EM ESTACAS SEMILENHOSAS DE ARAÇAZEIRO'
}

\author{
JOÃO GUILHERME CASAGRANDE JUNIOR ${ }^{2}$, VALMOR JOÃO BIANCH ${ }^{2}$, EDER ZARNOTT STRELOW ${ }^{3}$, \\ MARCOS ANTONIO BACARIN ${ }^{4}$ e JOSÉ CARLOS FACHINELLO 5
}

\begin{abstract}
RESUMO - O presente trabalho teve por objetivo avaliar a influência do sombreamento sobre os teores de carboidratos não-estruturais e fenóis solúveis totais em folhas e caules de estacas de plantas matrizes de araçazeiro (Psidium cattleyanum Sabine). Foram coletadas estacas semilenhosas em novembro de 1996, de plantas mantidas sob diferentes níveis de sombreamento (utilizou-se sombrite com malha comercial de 30, 50 e 70\% de redução da luz) e de plantas mantidas a pleno sol. Os teores de carboidratos solúveis totais, redutores, amido e fenóis solúveis totais foram determinados nas folhas e no caule de cada estaca. Com o aumento do sombreamento, observou-se uma elevação dos teores de amido e uma redução nos teores de carboidratos redutores nas folhas e no caule e, apenas no caule, uma redução dos carboidratos solúveis totais. Os compostos fenólicos foram reduzidos significativamente nas folhas, à medida que se aumentou a porcentagem de sombreamento, ao passo que nos caules verificou-se uma redução, mas pouco pronunciada, ratificando a afirmação de que plantas submetidas a condições de baixa radiação solar alteram seus teores de compostos de reserva e fenóis.
\end{abstract}

Termos para indexação: Psidium cattleyanum, luminosidade, substâncias de reserva, compostos fenólicos.

INFLUENCE OF SHADING ON THE CARBOHYDRATES AND PHENOLS IN CATTLEY GUAVA CUTTING

\begin{abstract}
The present work proposed to evaluate the influence of shading on the non-structural carbohydrates and total soluble phenols in leaves and stem of cutting, collected from cattley guava (Psidium cattleyanum Sabine) stock plant. The half-wood cuttings were collected in November of 1996, in plants kept under different shading levels (30, 50 e $70 \%$ of reducing light ) and plants kept full sun. The content of total and reducing soluble carbohydrates, starch and total soluble phenols were determined on the leaves and on the stem of each cutting. It was observed that with the increase of shading, there was a raise on starch content and a decrease on reducing carbohydrates content both on leaves and stems. Only on the stem a decrease on total soluble carbohydrates content was observed. The content of phenolic composts were reduced remarkably in the leaves with the increase of shading percentage. In the stems, a small reduction, not significant, was verified, confirming that plants at low sun radiation change their content of store and phenolic composts.
\end{abstract}

Index terms: Psidium cattleyanum, luminosity, store substances, phenolic composts.

${ }^{1}$ Trabalho aceito para publicação em 22 de setembro de 1998.

${ }^{2}$ Eng. Agr., Mestrando do curso de Fruticultura de Clima Temperado, FAEM-UFPEL, Caixa Postal 354, CEP 96001-970 Pelotas, RS. E-mail: vbianchi@ufpel.tche.br

${ }^{3}$ Estudante do curso de Agronomia, FAEM-UFPEL. Bolsista do CNPq.

${ }^{4}$ Eng. Agr., Dr., Prof. Adjunto, Dep. Botânica, IB-UFPEL, Caixa Postal 354, CEP 96010-900 Pelotas, RS. E-mail bacarin@ufpel.tche.br

${ }^{5}$ Eng. Agr., Dr., Prof. Titular, Dep. Fitotecnia, FAEM-UFPEL.

\section{INTRODUÇÃO}

O araçazeiro (Psidium cattleyanum Sabine) é uma espécie pertencente à família das mirtáceas e que apresenta grandes perspectivas de cultivo econômico a curto prazo. Pode ser encontrada desde Minas Gerais até o Rio Grande do Sul e na Região Nordeste do Uruguai, onde é uma das fruteiras nativas mais abundantes (Mattos, 1989; Raseira \& Raseira, 1990). Tal espécie possui alta potencialidade de utilização 
comercial, em face de apresentar alto teor de vitamina $\mathrm{C}$ de seus frutos, ótima aceitação para consumo in natura ou industrialização na forma de doces em pasta, geléias ou cristalizados, e baixa suscetibilidade a pragas e doenças (Nachtigal, 1994).

A propagação do araçazeiro é feita, basicamente, por sementes (Sanchotene, 1989). Porém, esse tipo de propagação promove a segregação e recombinação dos genes, acarretando grande variabilidade genética (Baldini, 1988). Segundo Voltolini (1996), pesquisas pioneiras com essa espécie, realizadas na Embrapa-Centro de Pesquisa Agropecuária de Clima Temperado, resultaram na seleção e lançamento de materiais genéticos com importantes características produtivas. Tais características, no entanto, só poderão ser passadas às gerações seguintes com a utilização de métodos de propagação vegetativa.

A propagação do araçazeiro pelo método da estaquia, tem possibilitado a obtenção de resultados promissores como os obtidos por Nachtigal et al. (1994) e Nachtigal (1994), mas ainda insuficientes para garantir sua recomendação e utilização prática, dada a necessidade de utilização de reguladores de crescimento, que torna o método caro (Voltolini, 1996).

Entre os fatores que afetam o enraizamento de estacas, Fachinello et al. (1994) citam as condições ambientais proporcionadas nesta fase e a translocação de substâncias localizadas nas folhas e caules; além disso, Hartmann \& Kester (1990) destacam a escolha do material para a estaquia, tratamento das estacas e fatores endógenos, pois a condição fisiológica da planta-matriz influencia fortemente o enraizamento.

Segundo Hess (1969), o aumento do teor de carboidratos e substâncias promotoras do enraizamento têm relação direta com incremento do potencial de enraizamento. Entretanto, existe uma exigência diferencial quanto aos níveis de carboidratos nas estacas para o sucesso do enraizamento (Wang \& Andersen, 1989).

Segundo Hartmann \& Kester (1990), ao se trabalhar com espécies de difícil propagação, como é o caso do araçazeiro, é possível obter maior porcentagem de enraizamento quando as plantas matrizes são mantidas sob baixos níveis de radiação solar. Tal afirmação concorda com os resultados ob- tidos por Voltolini (1996) e também com os trabalhos desenvolvidos por Herman \& Hess (1963), Hansen \& Eriksen (1974) e Harrison-Murray (1982), os quais encontraram que em plantas estioladas ocorre alteração dos teores de carboidratos, dos compostos fenólicos e dos reguladores de crescimento presentes nas folhas e caules, de maneira que a planta permaneça numa condição fisiológica em que o potencial de enraizamento é aumentado.

O presente trabalho teve por objetivo verificar a ocorrência de variações nos teores de carboidratos não-estruturais e fenóis solúveis totais em folhas e caules de estacas semilenhosas de plantas matrizes de araçazeiro, mantidas sob diferentes níveis de radiação solar.

\section{MATERIAL E MÉTODOS}

Estacas de araçazeiro foram coletadas de plantas matrizes com aproximadamente cinco anos de idade e cerca de $80 \mathrm{~cm}$ de altura, localizadas no pomar do Departamento de Fitotecnia da Faculdade de Agronomia Eliseu Maciel, em Pelotas, RS.

O sombreamento das plantas foi realizado com o auxílio de três túneis $(1,0 \mathrm{~m}$ de altura por $0,90 \mathrm{~m}$ de largura e $6 \mathrm{~m}$ de comprimento), cobertos totalmente com telas de polipropileno (Sombrite) com malha comercial de 30, 50 e $70 \%$ de sombreamento. Em cada túnel havia 12 plantas, e outro grupo com o mesmo número de plantas foi mantido a pleno sol ( $0 \%$ de sombra).

A coleta do material foi realizada em novembro de 1996, após um ano e oito meses de sombreamento. Foram coletadas três estacas de cada tratamento (doze no total), cada estaca constituindo uma única repetição, de onde foram retiradas amostras de folhas e ramos, que foram pesados e armazenados adequadamente, para análises posteriores de carboidratos solúveis totais, redutores, amido, e fenóis solúveis totais. O delineamento experimental foi inteiramente ao acaso, com três repetições, e para a comparação de médias foi utilizado o teste de Duncan a $5 \%$.

Os teores de carboidratos solúveis totais foram realizados com material fresco, após a extração com etanol $80 \%$, pelo método da antrona (Clegg, 1956). Do resíduo da centrifugação, após a extração dos carboidratos solúveis totais, foi extraído o amido e quantificado, segundo McCready et al. (1950). A quantificação dos carboidratos redutores realizou-se a partir do extrato de carboidratos solúveis totais, segundo a metodologia descrita por Dubois et al. (1956). A análise dos compostos 
fenólicos totais em água foi realizada pelo método Folin-Denis (Swain \& Hillis, 1959), usando floroglicina como padrão.

\section{RESULTADOS E DISCUSSÃO}

O aumento da intensidade do sombreamento provocou elevação dos teores de amido nas folhas e tendência à elevação destes no caule, como pode ser observado nas Figs. 1 e 2. Conjuntamente, pode ser observada uma diminuição dos teores de carboidratos redutores no caule e uma diminuição destes nos níveis $50 \%$ e $70 \%$ de sombreamento,

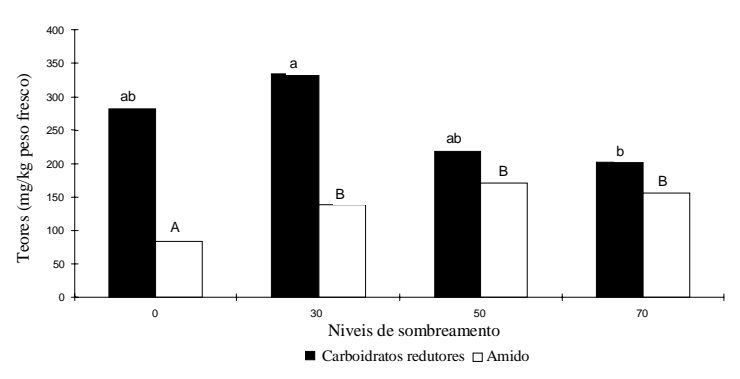

FIG. 1. Teores de amido e carboidratos redutores para folhas de araçazeiro, encontrados nos diferentes níveis de sombreamento, testados pelo teste de Duncan a 5\%. Letras maiúsculas são relativas a amido, e minúsculas, relativas a carboidratos redutores.

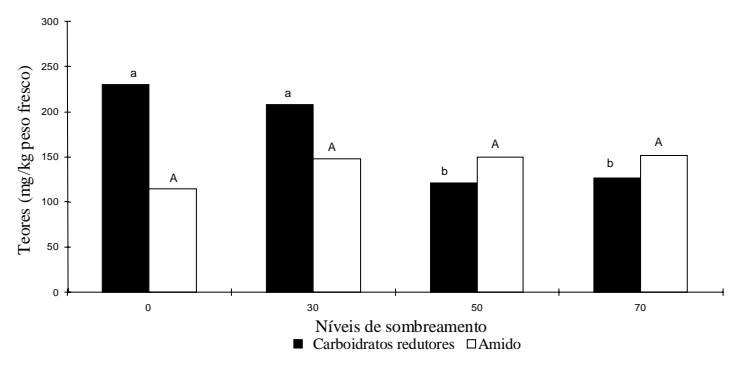

FIG. 2. Teores de amido e carboidratos redutores para caules de araçazeiro, encontrados nos diferentes níveis de sombreamento, testados pelo teste de Duncan a 5\%. Letras maiúsculas são relativas a amido, e minúsculas, relativas a carboidratos redutores. embora não tenham diferido da testemunha para as folhas.

Para a variável carboidratos solúveis totais foi observada uma leve tendência à diminuição desta, à medida que os níveis de sombreamento aumentam para o caule. Não foi verificada influência do sombreamento nessa variável, nas folhas (Fig. 3).

$\mathrm{O}$ aumento ocorrido nos teores de amido, nas folhas e caule, pode ser muito importante, pois, segundo Hess (1969), a capacidade de enraizamento está diretamente relacionada com o teor de carboidratos, de maneira que um aumento nos níveis destes, promoveriam maior porcentagem de enraizamento. Poulsen \& Andersen (1980), entretanto, afirmam que existe uma exigência diferencial entre espécies quanto aos teores mínimos de carboidratos na estaca, para que ocorra a iniciação das raízes.

Uma vez que ocorreu aumento do teor de amido, que é uma substância de reserva, é possível esperar que estacas submetidas aos níveis mais altos de sombreamento, além de terem maior capacidade de enraizamento, teriam ainda maior resistência em caso de condições adversas (baixas temperaturas, déficit hídrico, etc.) ao enraizamento, fato observado por Voltolini (1996), cujo material sombreado não só teve maior porcentagem de estacas enraizadas e maior número e comprimento de raízes, como também a mortalidade e a queda das folhas foi reduzida.

O teor de compostos fenólicos nas folhas diminuiu significativamente no nível de $70 \%$ de sombreamento, em comparação com a testemunha, como pode ser observado na Fig. 4. No caule, foi observada uma tendência de o sombreamento diminuir os teores de compostos fenólicos, se comparados com a testemunha. Esses resultados estão de acordo com o descrito por Herman \& Hess (1963), que, trabalhando com Vigna e Hibiscus, encontraram menor conteúdo de compostos fenólicos em tecidos estiolados dessas espécies. Segundo Hansem \& Eriksen (1974) e Hartmann \& Kester (1990), a redução da luz promove uma alteração do conteúdo de certos inibidores de crescimento naturais e dos compostos fenólicos.

Uma vez que os compostos fenólicos oxidam-se em contato com o oxigênio, esta reação causa a 
necrose dos tecidos, dificultando o enraizamento. Por esse motivo, a redução de compostos fenólicos no material utilizado para a propagação é de grande importância, principalmente nas espécies da família das mirtáceas, como é o caso do araçá, no qual a morte das estacas pela oxidação dos tecidos pelos compostos fenólicos é um sério problema e tem dificultado a propagação vegetativa. Verifica-se, pois, que o sombreamento é benéfico com relação ao preparo do material que será destinado à propagação vegetativa; porém, estudos complementares são necessários para avaliar qual a melhor porcentagem de sombreamento que proporcionará o melhor acúmulo de substâncias de reserva e redução de compostos fenólicos na espécie em

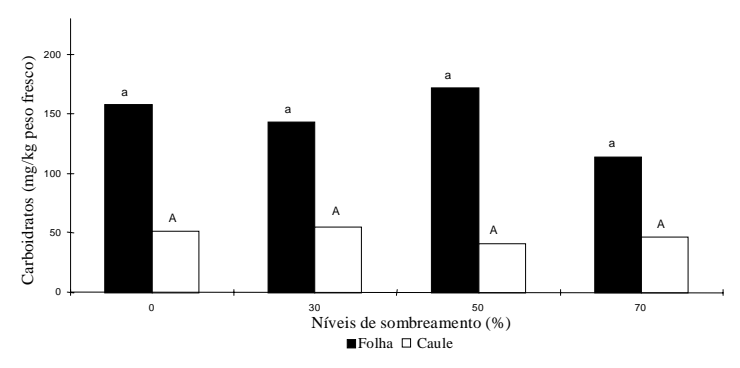

FIG. 3. Teores de carboidratos solúveis totais nos caules e folhas de araçazeito, encontrados nos diferentes níveis de sombreamento, testados pelo teste de Duncan a 5\%. Letras maiúsculas são relativas a caule, e minúsculas, relativas a folhas.

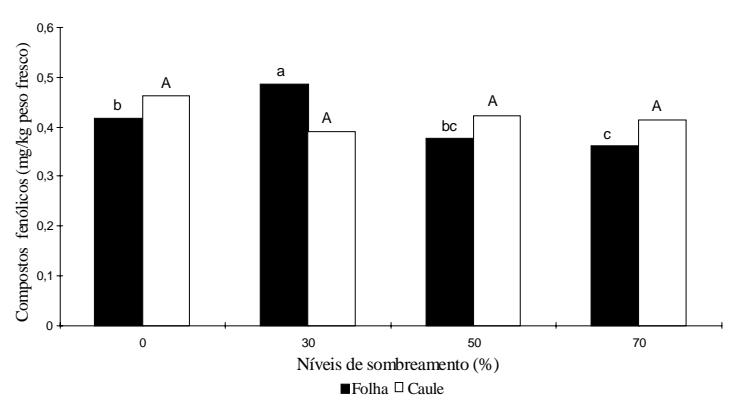

FIG. 4. Teores de compostos fenólicos solúveis totais nos caules e folhas de araçazeiro, encontrados nos diferentes níveis de sombreamento, testados pelo teste de Duncan a $5 \%$. Letras maiúsculas são relativas a caule, e minúsculas, relativas a folhas. estudo, bem como o melhor nível de enraizamento determinado por essa prática.

\section{CONCLUSÕES}

1. O aumento do teor de amido obtido em folhas e caules de araçazeiro apresenta uma relação direta com o aumento da porcentagem de sombreamento, sendo mais pronunciado nas folhas.

2. O teor de carboidratos redutores, em folhas e caules de araçazeiro, diminui à medida que aumenta a porcentagem de sombreamento das plantas.

3. O sombreamento não afeta significativamente o teor de carboidratos solúveis totais de folhas e caules de araçazeiro, mas estes apresentam uma pequena redução com a utilização dessa prática.

4. O aumento da porcentagem de sombreamento proporciona uma redução dos teores de compostos fenólicos das folhas e caule de araçazeiro, mas os efeitos são mais pronunciados nas folhas.

\section{REFERÊNCIAS}

BALDINI, E. Arboricoltura generale. Bologna: CLUEB, 1988. 360p.

CLEGG, K.M. The application of the anthone reagent to the estimation of starch in cereals. Journal of the Science of Food and Agriculture, v.7, p.40-46, 1956

DUBOIS, M.; GILLES, K.A.; HAMILTON, J.K.; REBERS, P.A.; SMITH, F. Colorimetric methods for determination of sugars and substances. Analytical Chemistry, v.28, p.350-356, 1956.

FACHINELLO, J.C.; HOFFMANN, A.; NACHTIGAL, J.C.; KERSTEN, E.; FORTES, G.R. de L. Propagação de plantas frutíferas de clima temperado. Pelotas: UFPEL, 1994. 178p.

HANSEN, J.; ERIKSEN, E.N. Root formation of pea cuttings in relation to the irradiance of the stock plants. Physiologia Plantarum, v.32, p.170-173, 1974.

HARRISON-MURRAY, R.S. Etiolation of stock plants for improved rooting of cuttings. 1. Opportunities suggested by work with apple. Proceedings of International Plant Propagation Society, v.31, p.386-392, 1982. 
HARTManN, H.T.; KeSTER, D.E. Propagación de plantas: principios y prácticas. Ciudad del México: Compañia Editorial Continental, 1990. 760p.

HERMAN, D.E.; HESS, C.E. The effect of etiolation upon the rooting of cuttings. Proceedings of International Plant Propagation Society, v.13, p.42-62, 1963 .

HESS, C.E. Internal and external factors regulating root iniciation. In: WHITTINGTON, W.J. (Ed.). Root growth. London: Butterworth, 1969. p.42-53.

MATTOS, J.R. Myrtaceae do Rio Grande do Sul Porto Alegre: CEUE, 1989. 721p.

McCREADY, R.M.; GUGGOLZ, J.; WENS, H.S Determination of starch and amylase in vegetables. Analytical Chemistry, v.22, p.1156-1158, 1950.

NACHTIGAL, J.C.; HOFFMAN, A.; KLUGE, R.A. ; FACHINELLO, J.C.; MAZZINI, A.R.A. Enraizamento de estacas semilenhosas de araçazeiro (Psidium cattleyanum Sabine) com o uso do ácido indolbutírico. Revista Brasileira de Fruticultura, Cruz das Almas, v.16, p.229-235, 1994.

NACHTIGAL, J.C. Propagação de araçazeiro ( Psidium cattleyanum Sabine) através de estacas semilenhosas. Pelotas: UFPEL, Faculdade de Agro- nomia Eliseu Maciel, 1994, 66p. Dissertação de Mestrado.

POULSEN, A.; ANDERSEN, A.S. Propagation of Hedera helix. Influence of irradiance to stock plant, length of internode and topophysis of cuttings. Physilogia Plantarum, v.49, p.359-365, 1980.

RASEIRA, A.; RASEIRA, M.C.B. Fruteiras nativas de clima temperado. Hortisul, Pelotas, v.1, p.47-51, 1990.

SANCHOTENE, M.C.C. Fruteiras nativas úteis à fauna na arborização urbana. 2.ed. Porto Alegre: SAGRA, 1989. v.14, 306p.

SWAIN, T.; HILLIS, W.E. The phenolic constituents of Prunus domestica. 1. The quantitative analysis of phenolic constituents. Journal of the Science of Food and Agriculture, v.10, p.63-68, 1959.

VOLTOLINI, J.A. Influência do sombreamento em plantas matrizes de araçazeiro (Psidium cattleyanum Sabine) para a produção de mudas por estacas. Pelotas: UFPEL, Faculdade de Agronomia Eliseu Maciel, 1996. 59p. Dissertação de Mestrado.

WANG, Q.; ANDERSEN, A.S. Propagation of Hibiscus rosa-sinensis: relations between stock plant cultivar, age, environment and growth regulator treatments. Acta Horticulturae, v.251, p.289-309, 1989. 